\title{
La fuerza invencible del (des) acuerdo: defensa eucarística en "Les epistres" de Gentien Hervet $(1499-1584)^{*}$
}

The invencible force of (dis) agreement: Eucharistic defense in “Les epistres" of Gentien Hervet (1499-1584)

\section{(4) Roberto Sánchez}

Universidad de Buenos Aires, Argentina

Fecha de recepción: Noviembre 2018. Fecha de aceptación: Noviembre 2018.

\section{Resumen}

Las cartas y discursos publicados por el teólogo y erudito humanista Gentien Hervet hacia 1561, demuestran la relevancia de la cultura impresa como herramienta para la transmisión de ideas. Sus vínculos con la industria editorial parisina le permitieron atacar a los calvinistas franceses en una acalorada disputa textual en torno al sagrado sacramento de la eucaristía, siendo éste un asunto clave para analizar el desencadenamiento de violencias continuas que pusieron en jaque la concordia en el reino.

\section{Palabras clave}

Gentien Hervet Guerras de religión francesas Eucaristía Disputas Teológicas Cultura Impresa

\begin{abstract}
The letters and discourses published by the theologian and Humanist scholar Gentien Hervet around 1561 demonstrate the relevance of printed culture as a tool for the transmission of ideas. His connections with the Parisian publishing industry allowed him to attack the French Calvinists in a heated textual dispute over the sacred sacrament of the Eucharist, which was a key factor to analyze in the outbreak of continuous violence that undermined harmony in the kingdom.
\end{abstract}

1

La febril sucesión de cartas y discursos escritos por el erudito Gentien Hervet en 1561, posee un evidente contenido religioso en clave polémica con el fin de señalar que "hors l'Eglise catholique il n'y a nul salut" (Hervet, 1561a: 23). A sus ojos, los reformados desdeñaban ridículamente del don de la salud; lógicamente, esto afectaba a la salvación de sus almas. Según el traductor, durante aquel momento histórico "on ne parloit d'autre chose que de pilleries o voleries, de sacagemens o massacremens de prestres"
Keywords

Gentien Hervet French wars of religion Eucharist

Theological Controversies Press Culture 
(Hervet, 1562: 8). Sin embargo, otro tipo de violencia, más sutil, se descargaba en los cuantiosos panfletos, discursos, epístolas y libros que, por entonces, se editaban y leían en público.

Hacia 1560, el débil poder político central encarnado por Catalina de Medici intentó, en vano, ajustar las riendas de sus súbditos. El canciller Michel de L"Hospital reunió en Orléans a los estados del reino sopesando las agudas divisiones existentes. Por su parte, la regente entendía que la pax política era inviable sin conciliación religiosa. Para ello, ordenó reunir en conferencia a prelados católicos, teólogos y ministros calvinistas en Poissy sobre el otoño del año siguiente. El fracaso de este coloquio puso de manifiesto que las discordancias en materia teológica eran mucho más profundas que el alcance de la diplomacia y la política. Sin embargo, un nuevo intento sería ensayado: el edicto de enero de 1562 reconocía a los protestantes el derecho a celebrar su culto en los espacios extramuros de las ciudades y en el medio rural. Al cabo de dos meses de firmada la orden, las tropas comandadas por Francisco, segundo duque de Guisa, descargaron su furia anti calvinista sobre un grupo de fieles en la llamada masacre de Vassy, profanando su espacio sagrado recientemente establecido.

2

El incesante trabajo de escritura iniciado por Hervet en 1561 respondía al agitado clima del que era partícipe. El impresor Nicolás Chesneau difundió el mensaje de aquel en un circuito de lectores laicos y del bajo clero que demandaban obras tan incendiarias como pedagógicas en libros in-octavo escritos en lengua vernácula. Si bien se trataba de un vínculo contractual, ambos hombres compartían una militancia de oposición a la política conciliadora urdida por la regente. ${ }^{1}$

En la Epistre ou advertissement au peuple fidele de l'Eglise Catholique, touchant les differens qui sont aujourd huy en la religion Chrestienne, Hervet manifestaba especial preocupación por el avance del fuego voraz de la herejía. Sostenía, además, que el dominio de la herejía se debía a que Dios nos sometía a prueba, tal como lo hizo con sus discípulos en el cenáculo, refiriéndose a lo recordado por el apóstol Pablo en la primera carta a los Corintios con la presentación del pan y el cáliz del Señor, y diciendo: "Que cada uno examine a sí mismo antes de comer este pan y beber esta copa; / porque si come y bebe sin discernir el cuerpo del Señor, come y bebe su propia condenación" (I CO 11: 28-29).

Al factor divino para el gobierno de la herejía se le sumaban elementos terrenales como "la mauuaise vie e conuersation, tant des ministres de l'eglise, que d"une grande partie du peuple" (Hervet, 1561b: 4). Al respecto, deseaba que la reanudación del Concilio de Trento (1545 - 1563) reformara el sacerdocio, suprimiendo "les gens indignes" en la administración de la fe. Podemos pensar que la necesaria reforma del clero apuntaba a acallar las críticas que, a partir del cisma luterano, se levantaban contra aquel y contra todo el régimen de sacramentos de obtención de la gracia impuesto por Iglesia católica. Los críticos negaban la eficacia de este sistema al considerarlo antes un producto humano que un signo visible de la gracia divina. Observamos que la actividad de Hervet no se agotaba en la instrucción a los católicos, ya que sus escritos buscaban, además, desafiar a quienes se atrevían a desmentir impunemente a Jesucristo cuando dijo: "Prenez et mangez, cecy est mon corps qui est livré pour vous. Et le calice est le nouveau testamenten mon sang, qui est respandu pour vous" (Hervet, 1561a: 8), porque manifestaban que el pan y el vino significan el cuerpo y la sangre respectivamente. La compleja idea de la significación era simplificada por Hervet en una pregunta: "Est ce pas autre chose d'estre e de signifier?". Y agregaba: "Or cecy est mon corps, est, est le mot expres. Et cecy signifie, est vn mot que vous tirez par force pour seruir a vostre incredulité" (Hervet,
1. La compleja relación entre escritor e impresor es explicada en Racaut (2009: 23-41). 
ibid.: 8, resaltado en el original). Lo que él señalaba como incredulidad ciertamente implicaba volver la espalda a la doctrina católica, a sus doctores y, lo que era peor, al Espíritu Santo. Su orgullo los conducía a contradecir el mensaje del propio Jesucristo: "Vous ne voulez pas qu'on le prenne icy, mais commandez qu'on l'aille prendre au ciel a la dextre de Dieu son père" (Hervet, ibid: 9).

La insistencia de Hervet en la disputa eucarística estaba vinculada con los sucesivos decretos del Concilio de Trento en la materia. En la sesión XIII, celebrada una década antes de la publicación de sus cartas, se confirmó la presencia real de Jesucristo en el sacramento de la eucaristía. Como corolario, los cánones declaraban anatema a quien negare que en dicho sacramento se contiene verdadera, real y substancialmente el cuerpo y la sangre juntamente con el alma y divinidad de nuestro Señor, creyendo que solamente está en él como señal, figura o virtualmente. Este énfasis continuó en las primeras sesiones luego del impasse, cuando se confirmó la doctrina de la comunión en ambas especies, y la regulación sobre la predicación y dispensa del sacramento. Por ello, creemos que las cartas de Hervet reservaban un triple propósito al tópico eucarístico: primero, el autor se presentaba haciendo propio el mensaje del concilio. Esta interiorización servía, luego, para difundir el mensaje y que otros lo adoptasen. Finalmente, sobrevenía el ataque hacia los ministros y fieles reformados, portadores de la gran llama que atacaba a la congregación católica y amenazaba con devorarla.

Sobre la eucaristía, el traductor de Orléans reafirmaba que la hostia es el precioso cuerpo de Cristo, ofrecido a Dios por intermedio de la Iglesia desde los tiempos de los apóstoles, en razón de los pecados de los vivos y los muertos. Así, negaba que fuera invención terrenal o un simple antídoto contra la incredulidad humana. Estas imprudencias no eran simple fruto de la ignorancia: Hervet creía que "nos aduersaires" estaban instigados por Satán, quien los había elegido como "seruiteurs propres pour faire sa besongne" (Hervet, ibid.: 22). Y expresaba que en su milenaria historia, la Iglesia católica supo enfrentar a este tipo de obstinados, contando entre éstos a: Berengario de Tours (998 - 1088), condenado en repetidas oportunidades por negar la presencia real y obligado a pasar el resto de sus días en el ostracismo; John Wycliffe (c. $1320-$ 1384), crítico radical tanto de las riquezas clericales como de la transubstanciación, condenado post mortem como hereje en 1415 durante el Concilio de Constanza; y Jan Hus (1369-1415), quemado en la hoguera durante dicho concilio. Así, entre la lección histórica y la amenaza, Hervet nos hacía saber que el triunfo de la Iglesia Universal era inexorable aunque hacia 1560 la cercanía del calvinismo era vivida como una amenaza concreta. Nunca antes la oposición entre el bien y el mal había sido tan manifiesta. La elección de los hombres por uno u otro bando en pos del mantenimiento de su salud era urgente, puesto que "Vous ne pouuez pas boire le calice du Seigneur, or le calice des diables: Vous ne pouuez pas estre participans de la table du Seigneur, o de la table des diables" (Hervet, ibid.: 10).

3

"Quant a moy, ie n'en croy rien: mais de cecy ie suis asseuré..." (Hervet, ibid.: 11)

A pesar de la suspensión del juicio, sus textos probaban las profundas creencias del orleanés. ¿Podemos encontrar, no obstante, cierto pensamiento escéptico en su obra? Trazar la recuperación del pirronismo en la Francia del siglo XVI excedería los objetivos de este trabajo. ${ }^{2}$ No obstante, es oportuno señalar la aparición de dos traducciones de la obra de Sexto Empírico (c 160 - c. 210) por aquellos años. La primera, en 1562, a cargo del reconocido savant Henri Estienne (c 1530 - 1598), quien publicó su traducción al latín de las Esquisses Pyrrhoniennes. La rápida adhesión de su padre
2. Un análisis más general de la recuperación del pirronismo en la cultura impresa del Renacimiento puede encontrarse en Floridi (1995: 63-85). 
a la Reforma obligó al joven Henri a dejar París por Ginebra. En el prefacio, Estienne reconocía que el encuentro con Sexto Empírico lo había ayudado a reponerse de "La maladie des Lettres". Quizás haya sido este poder sanador el mayor atractivo que pudiera haber encontrado un humanista reformado en el pirronismo. Pero la obra del médico y filósofo no quedó reservada a un único bando en la brecha confesional que dividía al reino galo. En 1569, Hervet publicó en París una versión latina del Adversus Mathematicos. Al respecto, Richard Popkin señaló que el traductor " put Pyrrhonism to work in the service of the Church" (Popkin, 1960: 67). En sus cartas, revisitaba la ortodoxia católica, presentando a través de ella, los principales puntos (errores) del calvinismo, pero evitaba discutir contra las razones naturales de éstos, argumentando que la fe y los sentidos no podían quedar sujetos a la esfera natural sino que debían humillarse sin reservas a la palabra todopoderosa de Dios ${ }^{3}$. En los años por venir, esta actitud influirá sobre la obra cumbre de otro fiel católico y brillante humanista: Michel de Montaigne (1533-1592). No son pocos los Essais donde el filósofo bordelés señala los desafíos que la concepción cristiana de la omnipotencia divina suponía para las capacidades humanas. En aquel contexto bélico, el escepticismo se exponía entre los católicos como un instrumento apologético de combate ante quienes les disputaban en materia de fe con las armas de la razón humana.

\section{4}

De acuerdo a la ficha biográfica de la Bibliothèque Nationale de France, Chesneau habría comenzado su actividad como impresor y grabador en París hacia 1556. Rápidamente obtuvo el privilegio de jurar como librero de la facultad de teología y para ratificar su deseo de éxito empresarial, hizo diseñar como lámina de imprenta una imagen que evocaba a la del reconocido editor e impresor de Basilea Johann Frobenius. A diferencia de esta última, Chesneau agregó una consigna en latín que rezaba "Concordia vis nescia vinci": la concordia es una fuerza que no puede ser vencida. Curiosamente, el impresor elogiaba la concordia a un tiempo que desafiaba las medidas de pacificación y acuerdo que buscaban apaciguar el agitado clima político, publicando virulentas cartas que inflamaban, aún más, las pasiones.

Por su parte, Hervet confesaba la cotidiana frustración que le provocaba ver nuevos adeptos a la secta. Sobre ésta, su mensaje era contundente: "I"esperoys que ces illicites conuenticules er sataniques assemblées deussent cesser" (Hervet, 1562: 4). Sin embargo, no había concilio de la Iglesia universal ni sínodo alguno del clero francés que pudiera detener un movimiento ávido por alcanzar la verdad en el Evangelio. Por ello, encontramos en su discurso un margen muy estrecho entre el deseo y la necesidad perentoria: es preciso actuar porque el tiempo se agota y el fin es próximo 4 . "Ce que considerant o iugeant le temps estre venu qu"il falloit qu'un chascun employast le talent que Dieu luy auroit donné, pour soustenir l'honneur de Iesus Christ e de son Eglise" (Hervet, ibid.: 5). Evidentemente, Dios le había ordenado a Hervet que mantuviera viva su pluma en las vehementes controversias de aquella década.

Para finalizar, resulta ilustrativo referir su descargo contra el pastor reformado Hugues Sureau du Rosier en L'Antihugues, publicado en Reims en 1567 por Jean de Foigny, impresor personal del Cardenal de Lorena, y comercializado en París por Chesneau. En uno de los numerosos apartados que reafirmaba la presencia del cuerpo y la sangre de Jesucristo en la eucaristía, podemos leer una frase muy propia de su tono y del contexto en que fue escrita: "Une telle doctrine deuroit elle pas estre exterminée er abysmée au profond d'enfer, d'ou elle est sortie?" (Hervet, 1567: 103). La pregunta, retórica en sí misma, apuntaba a revelar la imputación de desviación teológica bajo la sombra de la falsa, errónea y "diabolique religion", la cual "neantmoins au grand domage de la Chrestienté... est encore tolerée". Hervet denunció los saqueos, robos, quemas de "le ne veux pas entrer icy à disputer contre voz raisons naturelles, $\varepsilon$ monstrer qu'a ce qui concerne la foy, E les sens, \& la raison naturelle, se doibuent humilier $\&$ rendre subiects à la simple parole de Dieu, laquelle est toute puissante" (Hervet, ibid.: 9).

4. Resulta imposible no remitirnos a la explicación sostenida por Denis Crouzet sobre la expansión de la violencia religiosa al interior de la sociedad como resultado de la angustia generada por el temor a un apocalipsis inminente durante aquel turbulento siglo (Crouzet, 2005). 
iglesias, muertes de curas y otros inocentes. Pero no era una cuestión doctrinal la que estaba en juego solamente. Los calvinistas merecían recibir los rigores y severidades de las leyes antiguas por ser: responsables de las divisiones sociales, liquidar a la flor de la nobleza (como lo era Francisco de Guisa, el verdugo de Vassy); y ser partícipes directos de la conjuración contra Francisco II. Por su parte, los que ya habían sufrido un castigo fatal, "ont bien merité la mort".

La crudeza del relato nos obliga a recordar que Hugues Sureau (1530-1575) fue encarcelado en Septiembre de 1572 con el recuerdo todavía fresco de la espeluznante noche de San Bartolomé. Privado de su libertad, fue forzado a abjurar de su fe, ni más ni menos, que ante el rey Carlos IX; entretanto, su mujer y sus hijos escapaban de Francia. Una vez liberado, siguió sus pasos hacia Heidelberg, donde retomó la fe arrebatada hasta su muerte.

En el tono de las cartas y discursos escritos por Gentien Hervet en 1561 encontramos la piedra de toque de las guerras futuras. A pesar de haber sido aquel, el último año efectivo de paz, un fuego violento e impetuoso ya había comenzado a hacer arder las entrañas del reino. 


\section{Bibliografía}

"Crouzet, D. (2005). Les guerriers de Dieu : la violence au temps des troubles de religion, vers 1525 - vers 1610 . Champ Vallon, Seyssel.

"Floridi, L. (1995). "The diffusion of Sextus Empiricus's Works in the Renaissance". Journal of the History of Ideas, Vol. 56, $\mathrm{N}^{\circ}$ 1, (Jan.), pp. 63-85.

" Hervet, G. (1561a). Deux Epistres aux Ministres, Predicans et Supposts de la congregation et nouuelle eglise de ceux qui s'appellent fideles et croyans a la parole. Paris: Nicolas Chesneau.

" Hervet, G. (1561b). Epistre ou advertissement au peuple fidele de l'Eglise Catholique, touchant les differens qui sont aujourd'huy en la religion Chrestienne. Paris: Nicolas Chesneau.

» Hervet, G. (1562). Brief discours sur certain advertissement au lecteur, duquel les Ministres de la nouuelle Eglise reformée d'Orléans ont remparé une gentille response qu'ils ont faict imprimer, pour repondre aux Epistres de Gentian Hervet. Paris: Nicolas Chesneau.

» Hervet, G. (1567). L'antihugues, C'est a dire, Responce aux escrits \& blasphemes de Hugues Sureau, soy disant Ministre Caluiniste a Orléans, contre les principaux points de la Foy \& Religion Catholique. Reims: Jean de Foigny.

" Popkin, R. (1960). The History of Scepticism from Erasmus to Descartes. Assen: Van Gorcum.

"Racaut, L. (2009). "Nicolas Chesneau, Catholic printer in Paris during the French Wars of Religion", The Historical Journal, Vol. 52, № 1 (Mar.), pp. 23-41. 